\title{
Mandatory Reporting of Elder Abuse: Between a Rock and a Hard Place
}

\author{
Michael A. Rodríguez, MD, MPH \\ Steven P. Wallace, $\mathrm{PbD}$ \\ Nicholas H. Woolf, PbD \\ Carol M. Mangione, MD, MSPH \\ University of California, Los Angeles, \\ Los Angeles, Calif
}

\begin{abstract}
PURPOSE Despite mandated reporting laws that require physicians to report elder abuse, physicians have low rates of reporting. The purpose of this study was to identify physician's perspectives on mandated reporting of elder abuse.

METHODS Individual, semistructured interviews were conducted with 20 primary care physicians practicing in a variety of settings and caring for a diverse patient population in the Los Angeles area. Interviewers collected information on physicians' perspectives about factors that may influence physicians' likelihood to report elder abuse. The interviews were recorded and transcribed verbatim. Transcripts were analyzed using a grounded theory approach based on the constant comparative method and the emergence of the core category of paradox to best account for the most problematic elder abuse situations faced by physicians.
\end{abstract}

RESULTS During the interviews 3 paradoxes were expressed by physicians about the mandatory reporting of elder abuse. Specifically, mandatory reporting was related to both perceptions of increases and decreases in physician-patient rapport, patient quality of life, and physician control or ability to decide what is in the best interest of the patient. These paradoxes appear to be primarily hidden or unconscious, yet they influence the conscious decision process of whether to report.

CONCLUSIONS Primary care physicians appear to be subject to paradoxes of reporting that contribute to the underreporting of elder abuse. These paradoxes and alternative modes of managing paradoxes are important and should be addressed in educational and training programs for physicians, and systematic evaluation of these issues may help to inform future legislation in this area. Further studies are needed to assess the generalizability of these findings to other groups of clinicians.

Ann Fam Med 2006;4:403-409. DOI: 10.1370/afm.575.

\section{INTRODUCTION}

$\mathrm{D}$ espite the medical profession's focus during the last few decades on child abuse and intimate partner violence, there has been relatively little attention to elder abuse. Elder abuse is associated with physical and mental health problems, including physical injuries, depression, poor control of chronic diseases, and functional disability. Results of elder abuse can be devastating. During a 5-year period, nearly 114 elderly patients accounted for 628 emergency department visits seeking treatment for physical abuse. 'Mortality rates between 1992 and 2001 show that of 74 postmortem cases, 52 deaths were attributed to a homicidal act, and in 22 deaths neglect was suspected. ${ }^{2}$ Primary care may be a first response to abuse. In 2001, adults aged 65 years and older averaged 13.7 physician visits in the year. ${ }^{3}$ This level of interaction puts primary care physicians, who account for most visits, in a unique position to identify abuse and intervene.

Despite the serious health implications of elder abuse and high frequency of older persons' contact with physicians, health care clinicians detect and report abuse infrequently. ${ }^{4-6}$ The prevalence of elder abuse, including physical abuse, psychological abuse, financial exploitation, and
Michael A. Rodríguez, MD, MPH UCLA Department of Family Medicine 10880 Wilshire Blvd, Suite 1800 Los Angeles, CA 90024 MRodriguez@mednet.ucla.edu 
neglect, is between $2 \%$ and $10 \% \cdot{ }^{4,7-12}$ Risk factors include a shared living environment, cognitive or functional impairment, depression, and alcohol abuse. ${ }^{12-18}$ The American Medical Association (AMA) has advocated for health care professionals to assume a greater responsibility in addressing elder abuse. ${ }^{19}$ Based partially on the Older Americans Act of 1975, 33 states currently have some form of mandatory reporting of elder abuse. ${ }^{20}$ The terms and enforcement of such laws vary by state, however, and there is considerable debate over whether mandated reporting improves the lives of those it seeks to protect. ${ }^{21}$ These concerns may lead physicians to not report cases even when they appear., ${ }^{5,22,23}$

Some studies suggest that physicians' lack of familiarity with state reporting laws may contribute to underreporting of elder abuse, ${ }^{5,23,24}$ whereas others cite controversy over its effectiveness. ${ }^{22,25,26}$ Researchers have examined similar controversies concerning mandatory reporting of child abuse and intimate partner violence. ${ }^{27-29}$ Potential benefits of mandatory reporting laws include protecting the elder and removing from physicians the responsibility of deciding whether to report suspected incidents. Potential disadvantages, however, are that mandatory reporting may put abused elders at increased risk, diminish patient autonomy, and compromise patient-clinician confidentiality. ${ }^{21}$

Although mandatory reporting is the most commonly used policy intervention to address elder abuse, little research addresses factors promoting or inhibiting reporting. ${ }^{30}$ The extent to which the reporting process may actually discourage reporting is also understudied. In this article we describe primary care physicians' experiences and perspectives on the mandatory reporting of elder abuse.

\section{METHODS}

\section{Design}

We conducted individual in-depth, semistructured interviews with primary care physicians to investigate their perspectives on the detection and management of elder abuse in the outpatient setting. All study activities were approved by the UCLA Institutional Review Board.

\section{Settings and Participants}

We purposely sampled primary care physicians associated with 4 Los Angeles physician networks serving distinct geographic areas to reflect the sex and diverse ethnicity of Los Angeles physicians and their patient populations. We briefed physician leaders from each network on the study and distributed an informational letter about the study in the 4 physician networks. We contacted physicians who responded with interest in the study and, if eligible, we invited them to participate.
Eligible physicians were those who were family or general internal medicine physicians who spent at least $50 \%$ of their time in clinical practice in which at least $20 \%$ of their practice included patients aged 60 years or older. We initially contacted a total of 21 participants through a letter describing the study. Because 1 physician did not meet all eligibility criteria, this article reflects the responses of 20 participating physicians.

\section{Instrument and Data Collection}

We developed an interview guide based on reviews of the elder abuse literature and discussions with experts in elder abuse and geriatrics (Table 1). Interviewers trained in ethnographic techniques used open-ended questions to allow physicians to describe their experiences and perceptions about reporting patients who they believed had experienced or were at risk for elder abuse. Questions explored conditions that warrant reporting, experiences in reporting elder abuse, perspectives on the reporting law, and challenges to reporting. We pilot tested the interview to ensure appropriateness, measure duration, and maximize the completeness and quality of data. Interviews lasted approximately 35 to 60 minutes and were recorded and transcribed verbatim. After the interview, physicians completed a brief sociodemographic questionnaire to identify personal demographic characteristics.

\section{Table 1. Open-Ended Interview Questions}

We are interested in understanding physician's thoughts on addressing elder abuse in the outpatient clinical setting.

1. Please tell me about the kinds of elder abuse that a primary care physician might encounter in the outpatient setting?

2. Please tell me about any patients who, for whatever reason, made you think that they may be at risk for or may be experiencing elder abuse?

3. What might make you suspicious that a patient of yours was experiencing elder abuse?

4. What would you do if you become suspicious?

5. Is there anything else that a primary care physician might consider doing once there is a suspicion of elder abuse?

6 . Under what conditions if any would you report abuse?

7. Under what circumstances if any would you consider only monitoring?

8. Why do you think that patients who have been victims of elder abuse might be reluctant to bring this up with their primary care physicians at regularly scheduled visits?

9. Why do you think doctors may not address the topic of elder abuse, even if suspected during regularly scheduled visits?

10. How do you feel about the law that requires physicians to report suspected elder abuse?

11. What do you think could be done in your practice to help improve the effectiveness of physician efforts to address elder abuse?

12. What changes can be made to the clinic setting or environment that will help improve the effectiveness of physician efforts to address elder abuse?

13. Is there anything else that we haven't talked about that you would like to say about improving physician effectiveness in addressing elder abuse? 


\section{Data Analysis}

The goal of data analysis was to identify the core categories that represent the perceptions of physicians about mandatory reporting of elder abuse. Preconceptions approaching this study were that physician's would describe several barriers to mandatory reporting which would fall in the categories of patient, physician, and systems. Using a grounded theory approach, we used the constant comparative method $^{31}$ to compare iteratively segments of data to establish commonalties and consistencies that could be represented as codes. We compared, related, and clustered codes to determine higher-order categories that represented the major phenomena expressed by the participants; these phenomena were dilemmas, contradictions, and trade-offs. A core category of paradox emerged that accounted for the most problematic elder abuse situations expressed in these phenomena. A paradox is defined as a factor that simultaneously increases and decreases the likelihood of an event happening as result of an action, in this case the likelihood of reporting elder abuse. We then used the grounded theory principle of selective coding to relate all relevant categories as components of this core category and to set aside other categories. Ultimately 3 major paradoxes accounted for the majority of the most problematic situations.

ATLAS.ti software (Scientific Software Development, Berlin, Germany) was used to manage and code the data. Each transcript was coded by 2 research assistants, and all coding was reviewed and interpreted by a team of 3 researchers, including the first and third authors. The transcripts and higher-order categories underwent critical assessment at each stage, as well as consideration of alternative interpretations by an interdisciplinary team of reviewers, including the second and fourth authors, to reduce individual researcher bias. Selected quotations from the transcripts exemplify each paradox.

\section{RESULTS}

Of the participating physicians 10 (50\%) were male, and the mean age was 42 years (range 30 to 80 years). One (5\%) was African American, 4 (20\%) were Asian, $9(45 \%)$ were white, and 6 (30\%) were Hispanic/Latino. Twelve $(60 \%)$ were family physicians and 8 (40\%) were internists. The amount of time since graduation from medical school ranged from 4 to 49 years. Eight of the 20 participants $(40 \%)$ reported that they had experience detecting and reporting elder abuse, 10 (50\%) had identified potential elder abuse but had not reported it, and $2(10 \%)$ had neither detected nor reported elder abuse. Paradoxes emerged from analyses of interview transcripts related to 3 topical areas: (1) physician-patient relationship, (2) increase and decrease in patient quality of life, and (3) presence and loss of physician control. All 20 physicians referred to these paradoxes: 4 physicians referred to all 3 paradoxes, 8 referred to 2 of the paradoxes, and 8 physicians referred to 1 single paradox.

\section{The Paradox of Physician-Patient Rapport}

Ten $(50 \%)$ of the participating physicians were concerned about the contradictory effects of reporting elder abuse on patient rapport, which they believed both increased and decreased the likelihood of reporting. On the one hand, physician-patient rapport allowed for the trust and confidence that encouraged the patient to disclose abuse, increasing the likelihood of reporting, as described by this physician.

"I tell them that whatever they say is between me and them, and I'm not going to tell ... usually that tends to make people calm down to answer the questions more truthfully. ... I tell them that its going to be in their chart, but I am not going to necessarily run and report it.... 'I am going to talk to you, see what we can do, before we report it. And if not, if it's not fixable between us, then, yeah, I am going to have to.' And then they are, like, 'Well, okay'" (Female physician, No. 18).

On the other hand, physicians who built strong rapport over the years believed that their patients might feel deceived and let down if a report were made. This response inhibited reporting for fear that the close and valued relationship between the physician and patient would be harmed or severed by reporting.

"Once I step across the line, saying, 'I'm going to report you,' I lose all rapport with that family, my relationship with the patient is going to be altered forever, I will not continue to be maintained as their physician-even if it remains anonymous, it's not really anonymous-likely they're going to end up figuring out that it was probably me that did the reporting" (Male physician, No. 7).

Mandatory reporting laws in California state that suspected abuse must be reported. Some physicians noted, however, that suspicion is often a subjective judgment, and the expected loss of rapport caused by reporting raised the level of evidence they believed was necessary to suspect abuse, thereby inhibiting reporting.

"I think you really hurt the relationship of the family as a family, as well as with you, if you report prematurely or inadequately.... They're subjective decisions you make, unless there is obvious evidence of injury. They're very subjective, and you don't want to hurt the family or the relationship you have, so you want the strongest evidence that there is" (Male physician, No. 20).

Even when loss of rapport was not a concern, strong rapport with patient families could lead physicians to give the benefit of the doubt as to whether 
abuse is occurring and increase the required strength of evidence before reporting.

"Because you get to know the family very well - it's like not immediate but extraimmediate family — when they act up, you say, well, they had a bad day ... or whatever excuse you want to use, you are somewhat blind to what the problem really is. So in our field, where we get to know people very well, the tendency is to think better of people rather than worse of people

.." (Male physician, No. 7).

Whereas most physicians stated their support for mandatory reporting laws, in practice the paradox of rapport led to varying degrees of decision paralysis when they were faced with the reality of reporting.

"Well, I see why that law exists, but at the same time, if you are trying to get the patient to trust you and maybe tell you its happening, how can you, when they are suspecting you [will] report it? Then for sure they aren't going to tell you. So, you are kinda stuck between a rock and a hard place" (Female physician, No. 18).

Physicians work hard to establish rapport with their patients and families. It becomes a paradox when that relationship leads to disclosures, which, if acted on by reporting to an agency, can threaten the relationship.

\section{The Paradox of Patient Quality of Life}

Twelve participants $(60 \%)$ described some form of contradictory relationship between quality of life and reporting. This paradox concerns the contradictory effects of reporting in both improving and harming the patient's quality of life. A physician's desire to improve the patient's quality of life may encourage reporting to remove the elder from the abusive situation. But this desire of promoting the quality of life can also simultaneously decrease the likelihood of reporting, because physicians typically believed that the patient's quality of life might decrease in other ways as a result of reporting. After reporting to an adult protective services agency or the police, for instance, physicians expressed concern that the patient could be placed in an unwanted and unsatisfactory care environment, and cherished relationships with caregivers and family could be damaged, leading to greater abuse. Physicians attempted to balance the contradictory effects of reporting as part of making their judgment of whether they report suspected abuse.

"[Reporting about a negative outcome:] APS [Adult Protective Services] is not always helpful; in fact, sometimes they are destructive. I had one person who almost got kicked out of her apartment because of an APS report I made because she had been accosted or violated by the landlord of her apartment building.... They came out, they talked to the apartment manager, and they talked to the building owner, and the build- ing owner's response was, 'I want her out of here, she's trouble...' After they did their little intervention, they walked away, did not follow up with the patient at all, and so they didn't know that the landlord had this response and the patient was scared to death" (Female physician, No. 1).

Despite the negative outcome for this patient, this same physician did report an experience when the outcome was positive and beneficial to the patient. She described an occasion with an older female patient whose caregiver was an aging husband. The physician reported concern that the husband was unable to care for his wife's needs, but refused to seek outside help, thus potentially neglecting his wife.

"[Reporting a positive outcome of] a social worker who [was] doing great. Who got in there and got in their face and said to the family, you guys either straighten up, these are the rules, this will happen, she will be safe, or else you will not be responsible for her anymore. I will make sure that she's taken care of, but you will lose the ability to take care of her. She will become a ward of the state.... This guy really must have spent a lot of time understanding the family dynamics. And he was strong and directive when he needed to [be], and he also provided additional help. He was able to arrange in-home supportive services, he was able to provide some good listening" (Female physician, No. 1).

Other physicians described a case-by-case costbenefit evaluation of the contradictory effects of reporting before making a judgment of its merit.

"If I don't act, it's not going to get any better. If I act, that may cause more harm, but at least there's a chance that it's going to help and I think a better chance that it will help than not help. So I would say, you know, it's like anything else in life, you have to do the risk associated with it, and you've got to decide whether the benefit's worth the risk, and in [some cases] I would think reporting is worth it" (Male physician, No. 7).

Although elder abuse reporting laws tend to be absolute in requiring all suspected abuse to be reported, regardless of mitigating circumstances, in practice many physicians appear to consider the broader context of the consequences to the patient before reporting.

\section{The Paradox of Physician Control}

Eleven physicians (55\%) described some form of contradictory relationship between reporting suspected abuse and physician control. Physician control refers to the physician's perspective of the degree of control over the ability to do what is in the patient's best interest when facing conflicting choices. Mandatory reporting increases physician control over patient welfare by 
providing a powerful treatment tool when elder abuse is suspected. Although requiring reporting decreased the onus on physicians to make the decision to report, it simultaneously decreased physicians' exercise of judgment in how to improve patient welfare. Additionally, some physicians believed the law decreased control over their own situation by exposing them to potential legal liability if they did not report and malpractice liability if they did report, particularly should the suspicions turn out to be unfounded. One physician described her feelings of control over the welfare of her patients through abuse reporting.

"[Reporting requirement increases physician control:] I do think physicians have a duty to report something like elder abuse. Sometimes that's the only way, particularly if the individual is fragile and frail and has no relatives. [Reporting requirement decreases physician control:] But it's not recognized as being of any value by either an employer or an insurance company or the state. Every time you turn in a form, you put yourself at risk for liability.... We're not going to be reimbursed for any of this, so we need to be protected from lawsuits. The state needs to intervene and protect the physician, that's what would make [reporting] easier ..." (Female physician, No. 9).

Some physicians noted that the fear of liability led them to require absolute proof rather than suspicion of abuse before reporting.

"We always worry about malpractice situations; I am therefore very careful of what I say to any patient that could be misinterpreted. And saying that they are an abuse case, I would not flat out come out until I have absolute proof ..." (Male physician, No. 10).

The ways in which physicians managed the paradoxes of reporting suggest that the current laws do not take into account their contradictory impacts. It was a common sentiment that the black-and-white nature of mandatory reporting does not mesh well with the practice of primary care medicine.

"I think one of the problems that I see is that it's either black or white. It's either you report or you don't. There is nothing in between.... I guess being a physician, we want to give the benefit of the doubt.... The way that the system is set up right now, I am sure once you call the police, it's a very humiliating, embarrassing thing to go through. Ideally, it would be nice if I could have a system in between where we could have people come and work with the caregiver and try to figure out why they are hitting a defenseless person" (Male physician, No. 19).

Mandatory reporting laws can serve as a tool to provide leverage to the physician when working with patients, but those same laws can also threaten physicians regardless of the decisions to report or not respond to suspected abuse. For all 3 paradoxes, we found the responses that referred to these paradoxes of reporting were proportionately made by physicians who had neither detected nor reported abuse, had detected but not reported, and had both detected and reported. Thus, the paradoxes do not appear to be driven solely by firsthand experience. Finally, few physicians consciously recognized the interrelated influences in the paradoxes of reporting, and few described both contradictory effects in each case they discussed. Rather, these paradoxes appear to be primarily hidden or unconscious, yet they influence the conscious decision process.

\section{DISCUSSION}

This study was conducted to explore the perceptions and experiences of primary care physicians concerning the detection of elder abuse and the laws requiring reporting. Our goal was to begin the development of systematic and empirically derived knowledge about elder abuse reporting, resulting in a model that would be useful to clinicians and students who are being trained on issues of elder abuse. The findings of the 3 paradoxes, while powerful, were unanticipated and different from our preconceptions and led us to the decision to focus on these paradoxes.

The intent behind mandatory reporting laws is to bring abused elders and their abusers to the attention of appropriate authorities, such as an adult protective services agency. Although intended as a helpful intervention, the responses of the physicians we interviewed, regardless of ethnicity, sex, or experience with adult protective services, suggest that mandatory reporting laws create a number of unanticipated paradoxes in primary care practice. Paradoxes are a pervasive feature of our health care system in which the same factors that have steadily improved the health status of the population have also worsened perceptions of well-being and satisfaction with health care. ${ }^{32}$ Specific paradoxes have been noted in several areas of clinical practice, including the care of elders, ${ }^{33,34}$ and as a factor in the underreporting of child abuse. ${ }^{35}$ One review of the paradoxes in health care proposed a framework of 3 levels, from readily resolvable paradoxes based on only apparent contradictions, to more challenging paradoxes requiring a shift in perspective to reframe the situation, to paradoxes that cannot be resolved but simply must be endured. ${ }^{36}$

The paradox of physician-patient rapport appears to be an example of a third-level paradox, a situation that physicians may have to accept as not resolvable rather than take the course followed by several respondents, who, in the face of this paradox, concluded that their suspicions were not of sufficient gravity and took no action to report. Other respondents explicitly 
described efforts to delay a decision as long as possible as their way of accepting the paradox of rapport.

The paradox of quality of life appears to fall into the second level, where physicians may need to shift their perceptions to reframe the situation. Several physicians addressed this paradox on a case-by-case basis, reframing the problem as a cost-benefit evaluation of the potential effects of reporting on patient quality of life. In most cases physicians decided according to the ethical principals of beneficence in doing what they believed was in the best interest of their patient. This paradox suggests the need to improve systems of care that come into play when abuse is reported. Our findings indicate that physicians worry about unintended negative consequences of reporting elder abuse. It is important, therefore, to assess the effectiveness of mandatory reporting and its impact on the lives of the abused elder, the perpetrator, and the family so that physicians have strong evidence upon which to base their perceptions. The Institute of Medicine ${ }^{37}$ recommends systemic studies of reporting practices and the effects of reporting to help guide current and future policy making.

The paradox of physician control also appears to fall into the second level. Physicians concerned about the potential liability of reporting framed the problem in various ways, such as choosing not to interpret emotional mistreatment as reportable abuse or by requiring absolute proof before "suspecting" abuse, which have also been noted as barriers to mandatory reporting of intimate partner violence. ${ }^{28}$ Physician's perceptions may need to be reframed in this regard to appreciate their treatment options, in addition to reporting suspected abuse, rather than feeling controlled only by state mandates. Physicians may believe that evidence of elder abuse is not always indicative of current danger and seek alternatives to reporting for treatment. These physicians recognize that reporting and the subsequent investigation by an adult protective services agency can disrupt the lives of their elderly patients and may not ultimately be in the patient's best interests. Some physicians reported wanting to make social work referrals to experts connected with hospitals or other medical institutions as a first step for additional evaluation and treatment rather than immediately enmeshing a patient in an adult protective services system. The negative impact of the black-and-white nature of the reporting laws contribute especially to this paradox, and revisions to the legal mandates, as well as physician training, may be needed to improve the reporting system and patient care. Despite their legal concerns, no physician reported actual legal cases resulting from reporting or not reporting abuse to an adult protective services agency.

The results of this study reveal a need to increase awareness about elder abuse and knowledge of the laws about reporting elder abuse among primary care physicians. There are wide differences among states in reporting requirements for both the types of abuse, as well as the level of confidence that physicians must have before they report. Physicians in some states must report "reasonable cause to believe" there is abuse, whereas physicians in other states must "know" of or "observe" abuse before reporting. ${ }^{21}$ Despite these complications, laws are not often accompanied by changes in physician education or training, as was intended. ${ }^{21}$ In 2002, the Institute of Medicine's Panel on the Training Needs of Health Care Professionals in the area of Family Violence ${ }^{21}$ recommended that family violence training be integrated into all medical school teaching. Although much progress has been made in the areas of child abuse and intimate partner violence, it is unclear to what extent elder abuse training has been incorporated. It may be necessary to update existing policy and make training on elder abuse a requirement for medical licensure.

Several potential limitations of our study warrant comment. The lack of an iterative analysis/sampling strategy was a limitation. This study is the first of its kind, however, and for this first exploration, the primary objective of the selection process was to access a broad range of physicians by sex, ethnicity, and ethnicity of their patients. Future research is needed to validate these paradoxes as affecting mandatory reporting and to find out whether there are additional paradoxes. Another limitation is that the small sample of primary care physician cannot represent all primary care physicians. Obtaining information from physicians in states without mandatory reporting laws could offer distinctions in the effect of the mandatory aspect of the laws from the general issue of the way adult protective services systems are perceived to operate. Our analysis was also limited to primary care physicians, and it is equally important to examine the perspectives and experiences of other health professionals. There may be ways in which barriers to elder abuse reporting can be decreased. Almost all the physicians in our study explicitly expressed support for the concept of mandatory reporting, but their practice and implementation of this law were affected by their perceptions of the reporting paradoxes we identified. The passage of legislation has been a controversial issue among policy makers and physicians, as it is not always informed by systematic inquiry. Although a potential benefit of a mandatory reporting law is that it removes from the physician the responsibility of deciding whether to report, it potentially creates several additional concerns. The data-driven results of this study were analyzed using an iterative process of critical reflection and represent a first look at the physician's perspective 
on the legal mandates that have been passed. These results also suggest that further inquiry is needed to better address the needs of both physicians and their patients in the future. Greater reporting may be accomplished if the current reporting system were modified to reduce some of the paradoxes caused by the mismatch of the mandatory reporting laws and the realities of primary care practice.

To read or post commentaries in response to this article, see it online at http://www.annfammed.org/cgi/content/full/4/5/403.

Key words: Elder abuse; health care; reporting; qualitative; health care delivery; health services research

Submitted May 19, 2005; submitted, revised, January 20, 2006; accepted February 3, 2006.

Funding support: Dr Rodriguez was supported by the National Institutes of Health, National Institute of Aging, K23 AG00973 award. Both Dr Rodriguez's and Mangione's work on this project is also supported by the Resource Centers for Minority Aging Research/Center for Health Improvement of Minority Elderly (RCMAR/CHIME), funded by the National Institutes of Health, National Institute of Aging, grant No. P30 AG-21684.

Acknowledgments: We thank Hema Codathi Ramamurthi for her valu able contributions as the study coordinator.

\section{References}

1. Lachs MS, Williams C, O'Brien S, Hurst L, Horwitz R. Risk factors for reported elder abuse and neglect: a nine-year observational cohort study. Gerontologist. 1997;37:469-474.

2. Shields LB, Hunsaker DM, Hunsaker JC, 3rd. Abuse and neglect: a ten-year review of mortality and morbidity in our elders in a large metropolitan area. J Forensic Sci. 2004;49:122-127.

3. Federal Interagency Forum on Aging-Related Statistics. Older Americans 2004: Key Indicators of Well-Being. Federal Interagency Forum on Aging-Related Statistics. Washington, DC: U.S Government Printing Office; 2004

4. Lachs MS, Williams CS, O'Brien S, et al. ED use by older victims of family violence. Ann Emerg Med. 1997;30:448-454.

5. Clark-Daniels CL, Daniels RS, Baumhover LA. Abuse and neglect of the elderly: are emergency department personnel aware of mandatory reporting laws? Ann Emerg Med. 1990;19:970-977.

6. Barer BM. The secret shame of the very old: "I've never told this to anyone else." J Ment Health Aging. 1997;3:365-375.

7. Pillemer K, Finkelhor D. The prevalence of elder abuse: a random sample survey. Gerontologist. 1988;28:51-57.

8. The National Center on Elder Abuse. The National Elder Abuse Incidence Study. Available at: http://www.aoa.gov/eldfam/Elder_Rights/ Elder_Abuse/ABuseReport_Full.pdf. Accessed: 24 February 2005.

9. Podnieks E. National survey of elder abuse in Canada. J Elder Abuse Negl. 1993;4:5-58.

10. Reis M, Nahmiash D. Validation of the indicators of abuse (IOA) screen. Gerontologist. 1998;38:471-480.

11. Thomas C. The First National Study of Elder Abuse and Neglect: contrast with results from other studies. J Elder Abuse Negl. 2000;12:1-14.

12. Comijs HC, Jonker C, van Tilburg W, Smit JH. Hostility and coping capacity as risk factors of elder mistreatment. Soc Psychiatry Psychiatr Epidemiol. 1999;34:48-52.

13. Dyer CB, Pavlik VN, Murphy KP, Hyman DJ. The high prevalence of depression and dementia in elder abuse or neglect. J Am Geriatr Soc. 2000;48:205-208.
14. Godkin MA, Wolf RS, Pillemer KA. A case-comparison analysis of elder abuse and neglect. Int J Aging Hum Dev. 1989;28:207-225.

15. Lachs MS, Berkman L, Fulmer T, Horwitz RI. A prospective community-based pilot study of risk factors for the investigation of elder mistreatment. J Am Geriatr Soc. 1994;42:169-173.

16. Paveza GJ, Cohen D, Eisdorfer C, et al. Severe family violence and Alzheimer's disease: prevalence and risk factors. Gerontologist. 1992;32:493-497

17. Shugarman LR, Fries BE, Wolf RS, Morris JN. Identifying older people at risk of abuse during routine screening practices. J Am Geriatr Soc. 2003:51:24-31.

18. Vida S, Monks RC, Des Rosiers P. Prevalence and correlates of elder abuse and neglect in a geriatric psychiatry service. Can J Psychiatry. 2002;47:459-467.

19. American Medical Association. Diagnostic and treatment guidelines on elder abuse and neglect. Available at: http://www.amaassn.org/ama1/pub/upload/mm/386/elderabuse.pdf. Accessed: 24 February 2005.

20. National Center on Elder Abuse. A Response to the Abuse of Vulnerable Adults: The 2000 Survey of State Adult Protective Services. Available at: http://www.elderabusecenter.org/pdf/research/apsreport030703.pdf. Accessed: 24 February 2005.

21. Cohn F, Salmon ME, Stobo JD, eds. Confronting Chronic Neglect: The Education and Training on Family Violence. Washington, DC: National Academy Press; 2002.

22. Rosenblatt DE, Cho KH, Durance PW. Reporting mistreatment of older adults: the role of physicians. J Am Geriatr Soc. 1996;44:65-70.

23. Jones JS, Veenstra TR, Seamon JP, Krohmer J. Elder mistreatment: national survey of emergency physicians. Ann Emerg Med. 1997:30:473-479.

24. Daniels RS, Baumhover LA, Clark-Daniels CL. Physicians' mandatory reporting of elder abuse. Gerontologist. 1989;29:321-327.

25. Brewer RA, Jones JS. Reporting elder abuse: limitations of statutes. Ann Emerg Med. 1989;18:1217-1221.

26. Salend E, Kane RA, Satz M, Pynoos J. Elder abuse reporting: limita tions of statutes. Gerontologist. 1984;24:61-69.

27. Rodriguez MA, Craig AM, Mooney DR, Bauer HM. Patient attitudes about mandatory reporting of domestic violence. Implications for health care professionals. West J Med. 1998;169:337-341.

28. Rodriguez MA, McLoughlin E, Bauer HM, Paredes V, Grumbach K. Mandatory reporting of intimate partner violence to police: views of physicians in California. Am J Public Health. 1999;89:575-578.

29. Vulliamy AP, Sullivan R. Reporting child abuse: pediatricians' experiences with the child protection system. Child Abuse Negl. 2000:24:1461-1470.

30. Watzlawick P, Beavin JH, Jackson DD. Pragmatics of Human Communication: A Study of Interactional Patterns, Pathologies, and Paradoxes. New York, NY: W. W. Norton; 1967.

31. Grounded theory methodology - an overview. In: Denzin NK, Lincoln YS, eds. Handbook of Qualitative Research. Thousand Oaks, Calif: Sage Publications; 1994:273-285.

32. Barsky AJ. The paradox of health. N Engl J Med. 1988;318:414-418.

33. Henriksen E, Rosenqvist U. Contradictions in elderly care: a descriptive study of politicians' and managers' understanding of elderly care. Health Soc Care Community. 2003;11:27-35.

34. Loew F, Rapin $\mathrm{CH}$. The paradoxes of quality of life and its phenomenological approach. J Palliat Care. 1994;10:37-41

35. Overholser JC. Ambiguity, barriers, and contradictions: the ABCs of child abuse allegations. Issues Child Abuse Alleg. 1991;3. Available at: http://www.ipt-forensics.com/journal/volume3/j3_2_3.htm.

36. Hofmann B. The paradox of health care. Health Care Anal. 2001;9:369-386.

37. Bonnie RJ, Wallace RB, eds. Elder Mistreatment: Abuse, Neglect, and Exploitation in an Aging America. Washington, DC: National Academy of Sciences; 2003. 